\title{
Cancellation of basic income project a blow to health research
}

Cite as: CMAJ 2018 August 27;190:E1024-5. doi: 10.1503/cmaj.109-5648

Posted on cmajnews.com on Aug. 7, 2018.

$\mathrm{T}$ here is no debate in medical circles about the link between poverty and poor health. In a list of determinants of health, the World Health Organization put income and social status at the top. And according to the Institute for Research on Poverty, social and economic factors "are likely even more important to health outcomes than health behaviours and clinical care." In 2017, the Northern Policy Institute, an independent think tank in Northern Ontario, examined the impact of a basic income guarantee on food security. For problems of food insecurity, "the only common denominator is inadequate, insecure incomes," stated the institution.

So it comes as little surprise that the decision by Ontario's new Progressive Conservative government to cancel a basic income pilot project has raised concerns in the medical community. The project, which provided about 6000 people in Ontario with an annual income that was double standard welfare rates, was started by the province's former Liberal government in hopes it would lead to improvements in participants' education, employment, housing, nutrition and overall health. According to a discussion paper on the project, some of the key outcomes that would be measured included number of primary care visits, number of emergency department visits and prescription drug use.

The project was intended to run for three years but was cancelled after only one. That's unfortunate, according to Dr. Kwame McKenzie, a psychiatrist and special advisor on the project, because the three-year window would have provided enough time to make meaningful conclusions. "So, one of the reasons for

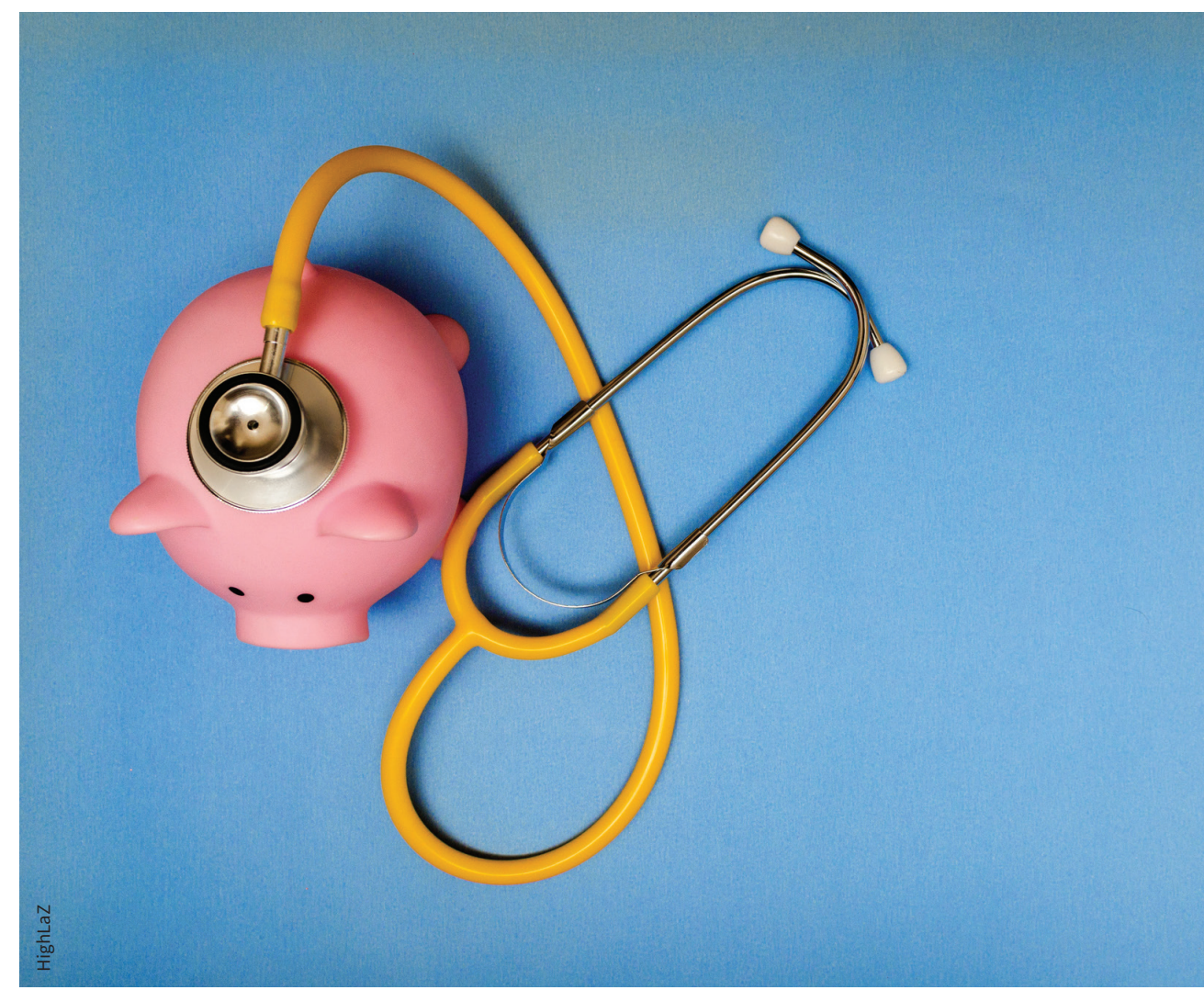

Healthier incomes lead to better health outcomes.

doing it was to say, 'Well, does that actually work here in Ontario? And does the same intervention, which is a way of getting people out of poverty, work as well here as it's worked in other places?"' he said in a CBC interview. "And now, I guess we'll never know."

Data from the Ontario project would have been a welcome addition to the farfrom-robust body of evidence on the effects of basic income guarantees on health outcomes. Much of the existing literature is based on older projects, or on experiments that focused on outcomes not related to health.
A 2011 analysis of a guaranteed annual income experiment conducted in Canada in the 1970s found several public health benefits. The experiment was conducted at several locations in Manitoba from 1974 to 1979 . There were fewer hospitalizations among the 900 families in the experiment, especially for mental health problems and injuries from accidents, than in a comparison group of 467 families matched by age, gender, geography and family size. One theory suggested to explain this finding is that workers receiving a basic income were less likely to suffer from stress related to financial worries and, therefore, also less 
likely to compromise personal safety in the work environment for income.

The authors suggested that guaranteed incomes, if implemented broadly in society, would likely improve health and social outcomes at the community level. "At the very least, the suggestive finding that hospitalization rates among Dauphin subjects fell by $8.5 \%$ relative to the comparison group is worth examining more closely in an era characterized by concern about the increasing burden of health care costs," stated the authors.

Basic income projects conducted in other countries have also shown positive effects on some health outcomes. A pilot project conducted in Madhya Pradesh, India, between 2011 and 2012 involving 2034 households found that it reduced minor illnesses and injuries by $46 \%$. It did not show any effect, however, on more serious illnesses and injuries or on rates of childhood vaccination. A similar project in Namibia, Africa, in 2008 saw a drop in child malnutrition and found that rural residents with guaranteed income were more likely to attend regular medical appointments.

Overall, however, experiments of various forms of income supplementation, including basic income guarantees, have done a poor job of examining how they affect health outcomes, according to a systematic review of research conducted on this subject. "Extensive opportunities to reliably assess the effects of increases in income on health outcomes have been missed," the authors concluded. "Such evidence might have increased the consideration of potential health effects during deliberations about policies that have major implications for income, such as taxation rates, benefit policies, and minimum wage levels."

Roger Collier, CMAJ 